\title{
Research on the scope of patent protection of Chinese ceramic products Xiao Liang dong
}

\author{
Jingdezhen ceramic university, China
}

Key words: ceramic products; appearance design; patent right; protection scope; definition

Abstract: Ceramics is the world's Chinese symbol. In the process of Chinese ceramic product appearance design, it will involve the legal protection of the appearance design. Therefore, it is necessary to define the scope of the patent right of ceramic appearance design. In the process of defining the scope of patent right of ceramic product appearance design, it is necessary to understand the legal protection scope of ceramic product appearance design in detail. Therefore, this paper focuses on the scope of patent protection of ceramic product appearance design, in order to clear the scope of patent protection.

\section{Introduction}

Ceramic product appearance design patent right, belong to a product type monopoly rights, can effectively expand the market influence of ceramic products. However, the scope of protection of some ceramic product appearance design patent is too narrow, it will hinder the development and use of rights, the protection scope of some rights is too broad, and will be improper use, there will be some damage to the interests of others. Therefore, it is very necessary to define the protection scope of ceramic products appearance design patent.

\section{The protection scope of the ceramic product appearance design patent right}

According to the "Rules for The Implementation of The Patent Law" of our country, the appearance design of the product mainly refers to mainly refers to a regulation of the external shape of the product, the design of the product, the shape of the flower, the use of color, etc. And combine these elements together to form a kind of aesthetic, artistic product design concept, has been widely used in industrial production process. Appearance design is also called "new design" ${ }^{[1]}$. This "new design" is based on Consumers' cognitive ability, judgment ability, aesthetic ability and so on; In the process of technological development, this "new design" may contain a similar appearance design, but the similarities between the two are essentially different. Therefore, it is necessary to define the applicable scope of the relate appearance design patent right. In the "Patent Law", the patent protection scope of product appearance design mainly from the product appearance design in the use of pictures, patterns and other content as the scope of the definition of protection. However, the "Patent Law" in the actual implementation process has a contradiction, it is easy to appear patent infringement of product appearance design patent infringement. Therefore, it is necessary to further study the scope of patent protection of appearance product design, to ensure the normal implementation of relevant laws and regulations

\section{The definition of product classification in the scope of patent protection}

For design patent applications for the appearance design of products, in general, the appearance design patent of a product is mainly concentrated on a particular appearance design, The "Patent Law" promulgated by the state refers to the application of the patent for the appearance design of the product, for the same category of product appearance design, can be seen as a product appearance design patent application. In the development process of the ceramic industry, the scope of ceramic products involves a wide range, such as sets of ceramic tableware are the same category. When applying for the patent right for appearance design of this kind of ceramic products, it is necessary to specify the type of product design ${ }^{[2]}$, once the applicant is in the process of designing the patent application, forget to indicate the product category, at the National Patent Office review process, will be reclassification of this kind of products, in accordance with the classification standards related to these products will be divided into specific categories, so it is easy to appear the scope of protection of patents of chaos. 
Therefore, in the process of defining the scope of patent protection of ceramic product appearance design, we need to be based on the relevant "Product Classification List", and define the scope of patent protection of product appearance design, it is necessary to make clear the focus of patent application, and highlight the uniqueness of product design ${ }^{[3]}$. First of all, it is necessary to take into account the scope of the protection of ceramic product appearance design, it is necessary to pay attention to the appearance design of ceramic products are accused of infringement, at the same time, it is clear that the ceramic product appearance design patent in the marketing process, whether there will be confusion of ceramic products and other issues, in addition, according to the consumption of ceramic products in the market and consumer consumption concept, the scope of patent protection for the design of ceramic products are defined, the exact classification of ceramic products. Secondly, to clear the appearance design patent of ceramic products the protection scope of a patent infringement is defined in the design patent of ceramic products, to be able to quickly from the actual market situation of ceramic products analysis, master ceramic products consumer market share, in simple terms, when the two kinds of commodities of the same design, but two kinds of ceramic products in the market share of consumption has no mutual interference, it can be design patent protection scope of this two kinds of ceramic products are defined as similar products, but these two kinds of ceramic products can not be judged as infringement.

\section{The definition of color in the scope of protection of the patent right}

In the process of product appearance design, color is essential, but also an important part of product appearance design. In the process of ceramic product appearance design patent protection range in color definition, need to account for the proportion and the function of color in product design are analyzed, so as to accurately determine the scope of protection of the product appearance design ${ }^{[4]}$. The greater difference between the appearance design of a product in the image, shape and other aspects of the existing products, the role and value of color in product appearance design patent protection will be significantly reduced. When the appearance of a product in the design of the external shape of the product, the image and other aspects of the existence of the difference between the smaller the product, the role of color in the design of the patent protection scope of the product is more prominent. At the same time, we should also take into account the proportion of color in the entire product design patent, If the color as an important factor in the protection of product design patent protection, it is necessary to shape the design of the product, color design and other aspects of innovation, in this way can we form a kind of innovative products.

According to the "Rules for The Implementation of The Patent Law" of our country, in the process of product design patent application, it is necessary for the applicant to design the product image, shape and other content to protect the scope of application, at the same time, it also needs to be used in the design of the product color to define the scope of protection, and as the color and shape, image and other content a certificate to apply for design patents ${ }^{[5]}$. When the product appearance design patent applicants applies for the design color protection, it is necessary to define the scope of the product's color protection, and to protect the color of the product. As for the product appearance design patent applicants to protect the product appearance color, they need to clearly specify a unique product design color, in order to protect the color process, focusing on the protection of a particular color. Therefore, in the process of defining the scope of patent protection of ceramic product appearance design, we need to accurately grasp the color in the product appearance design patent protection scope of the role, so in the design process of patent application, detailed provisions of the product design patent in the scope of color protection.

\section{Concluding remarks:}

In summary, in the process of patent protection of ceramic appearance design, it is necessary to analyze the scope of patent protection of ceramic appearance design, find out the factors that affect the scope of patent protection, for further exploration, to make clear that the patent right of design will be affected by the types of products involved. In the process of the actual appearance design of ceramic products, according to the types of ceramic products, the scope of protection of the 
corresponding products is made, so as to further improve the efficiency and level of product design. At the same time, the color of the product appearance design, will also affect the scope of the product design patent protection.

\section{Reference:}

[1] $\mathrm{Xu} \mathrm{Xin}$. The principle of interpretation of the scope of protection of design patent--From the perspective of judging the infringement of design patent[J].intellectual property right, 2016 (09).

[2] Wang Peng, Xie Donghui, Ma Yuefei. Functional appearance should be excluded from the scope of protection of design patent, [J]. people's justice, 2015 (12).

[3] Li Hong. The significant progress in the protection of design patent--from the perspective of the third revision of the patent law [J]. Journal of China Youth University for Political Science, 2014 (07).

[4] Yi Junxiong, Wang Wei. Discussion on infringement judgment standard -- from two cases [J]. Journal of Hubei University of Police, 2012 (03).

[5] Guan Jian, Zeng Zhen, Du Nan. Analysis of the impact of product use on the scope of protection of design patent $[\mathrm{J}]$. China invention and patent, 2013 (11). 